\title{
Effect of Calcium Lactate on Quality, Safety and Nutritional Senescence Parameters of Minimally Processed Vegetables
}

\author{
Ana Belen Martin-Diana \\ Technological University Dublin, anabelen.martindiana@tudublin.ie \\ Daniel Rico \\ Technological University Dublin, daniel.rico@tudublin.ie \\ Jesus Maria Frias \\ Technological University Dublin, Jesus.Frias@tudublin.ie
}

See next page for additional authors

Follow this and additional works at: https://arrow.tudublin.ie/tfschafart

Part of the Food Science Commons

\section{Recommended Citation}

Martin-Diana, A. B., Rico, D., Frias, J., Mulcahy, J, Henehan, G. T. M. and Barry-Ryan, C. Effect of Calcium Lactate on Quality, Safety and Nutritional Senescence Parameters of Minimally Processed Vegetables. Acta horticulture, 687, 2005. DOI: 10.21427/d76t9r

This Article is brought to you for free and open access by the School of Culinary Arts and Food Technology at ARROW@TU Dublin. It has been accepted for inclusion in Articles by an authorized administrator of ARROW@TU Dublin. For more information, please contact arrow.admin@tudublin.ie, aisling.coyne@tudublin.ie, gerard.connolly@tudublin.ie.

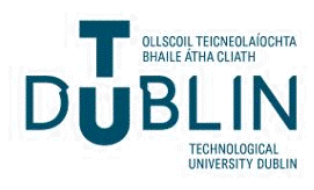




\section{Authors}

Ana Belen Martin-Diana, Daniel Rico, Jesus Maria Frias, Jemina Mulcahy, Gary Henehan, and Catherine Barry-Ryan 


\title{
Effect of Calcium Lactate on Quality, Safety and Nutritional Senescence Parameters of Minimally Processed Vegetables
}

\author{
A.B. Martin-Diana, D. Rico, J. Frias, J. Mulcahy, G.T.M. Henehan and C. Barry-Ryan \\ School of Food Science and Environmental Health. Postharvest Unit. Dublin Institute of \\ Technology (DIT). Cathal Brugha Street, Dublin 1 \\ Ireland
}

Keywords: Salad-cut lettuce, sliced carrots, senescence indicators, browning, texture, safety

\begin{abstract}
Calcium lactate maintained quality senescence indicators, as well as chlorine in Iceberg lettuce, and enhanced nutritional values during storage in sliced carrots better than chlorine. Colour and texture objective measurements did not show differences between treatments for Iceberg lettuce; however there were differences in colour in sliced carrots, showing greater change in colour values in samples treated with chlorine. Calcium lactate washing treatments prevented the bleaching effect on saladcut lettuce and sliced carrots and also diminished the appearance of white surfaces over storage. The ascorbic acid decreased during storage independently of the type of treatment used for both vegetables, however the carotenoid content showed higher values in sliced carrots treated with calcium lactate than treated with chlorine at the end of the storage. A sensory panel could not find significant acceptability differences between treatments at the end of storage for either vegetable. Mesophiles, psycrophiles and lactic acid bacteria counts were not significantly different between both treatments. The calcium lactate $(3 \%)$ maintained quality of the vegetables as good as $120 \mathrm{ppm}$ of chlorine, thus it can be considered as a good alternative washing treatment from a quality point of view.
\end{abstract}

\section{INTRODUCTION}

The increasing demand for "ready-to-eat" (RTU) vegetables has prompted the sale of pre-cut vegetables (Iceberg lettuce and carrots specially). Some consumer trends affecting the industry include lifestyle and demographic changes, competitive market place and changing consumer tastes. These trends create a push for convenient food products with a high degree of freshness that has led food manufacturers to develop various products in an effort to provide the freshness through minimal processing, without compromising food safety or the health of the consumer.

Chlorine solutions (50-200 $\mathrm{mg} / \mathrm{L})$ are widely used to wash fruits and vegetables as well as fresh cut produce in order to reduce microbial growth (Beuchat, 1999). The possible formation of carcinogenic chlorinated compounds in water (chloramines and trihalomethanes) has called into question the use of chlorine for this purposed (Page et al., 1993). There have been many attempts to find alternative washing treatments to chlorine (Artes et al., 1999). These include the use of organic acids and ozone, among others. The use of calcium salts are attractive as alternative washing treatments for several reasons. These compounds are inexpensive, simple, natural and non-toxic. Of the many calcium salts, calcium lactate has the advantage that it avoids the bitterness or off-flavours associated with other salts (Luna-Guzman and Barrett, 2000).

The objective of this study was to comprehensively evaluate the use of calcium lactate as a washing treatment for "Ready to use" (RTU) vegetables and compare it with the widely used chlorine treatment. Quality and nutritional senescence indicators were used to compare both treatments.

\section{MATERIALS AND METHODS}

Iceberg lettuce (Lactuca sativa sp.) grown in Ireland and carrots (Daucus carota $s p$.) grown in France were prepared by minimal processing procedures. The carrot slices 
and salad-cut lettuce were dipped in $12 \%$ active chlorine and $3 \%$ calcium lactate solution for $5 \mathrm{~min}$ at room temperature. The processed vegetables were packaged in oriented polypropylene (OPP) and stored at $4{ }^{\circ} \mathrm{C}$. Over 10 days, physiological parameters were evaluated.

Headspace gas composition was measured using a Gas analyser. Exudate (Carlin and Nguyen-the, 1999), dry matter, total carotenoids (Gross, 1991) and ascorbic acid (AOAC, 1995) levels were monitored over the 10 days. Enzymes involved in browning, polyphenol oxidase (PPO) (Tan and Harris, 1995) and peroxidase (POD), were measured spectrophotometrically. Colour parameters (CIE Lab*) were quantified using a colorimeter (ColorQuest XE) and digitally obtained images, processed with Adobe Photoshop ${ }^{\circledR}$. Texture properties were measured with an Instron Universal Testing Machine (Instron 4302, Canton MA, USA) and Pectin methyl esterase (PME) activity quantified (Kimball, 1991). Appearance, aroma, texture, taste, and overall acceptability of samples were scored on a hedonic scale of 1 to 10 . The sensorial analysis was carried out with Compusense ${ }^{\circledR}$ Five (Release 4.4, Ontario, Canada).

Samples packages were examined during storage using the microstructure was observed by Cryo-SEM in a JEOL JSM-5410 microscope. The samples were cryo-fixed by immersion in slush nitrogen $\left(-210^{\circ} \mathrm{C}\right)$. Samples were then fractured, etched (at $94.5^{\circ} \mathrm{C}, 10^{-5}$ torr for $15 \mathrm{~min}$ ), gold coated and viewed in the cold-stage SEM. The fracture surface of the cryo-fixed samples was viewed directly while it was maintained at $150^{\circ} \mathrm{C}$. Samples were frozen and fractured as described earlier and specimens were scanned at the cold stage temperature of $-135^{\circ} \mathrm{C}$ using an accelerating voltage of $15 \mathrm{kV}$.

For microbiological studies $10 \mathrm{~g}$ of vegetable was homogenised in $90 \mathrm{~mL}$ of peptone saline with a Stomacher circulator homogenizer. Enumeration and differentiation of microorganisms were carried out as follows: mesophilic aerobic bacteria were quantified at $30{ }^{\circ} \mathrm{C}$ in plate count agar (PCA) over 72 hours. Psychotrophic bacteria were quantified in plate count agar (PCA) at $21^{\circ} \mathrm{C}$ over 25 hours. Enumeration of lactobacilli was carried out using DeMan rogosa sharpe agar (MRS) at $35^{\circ} \mathrm{C}$ over 48 hours. Two independent runs were performed to analyse the effects of chlorine and calcium lactate. All assays were carried out in duplicate.

\section{RESULTS AND DISCUSSION}

Oxygen content decreased during storage and carbon dioxide increased significantly for both treatments and in both vegetables. In cut-salad lettuce, at days 1 to 3 , small changes in the gas concentration were appreciated for chlorine and calcium lactate treated samples (Fig. 1-i) however, by day 7 the oxygen content had decreased significantly for both treatments, resulting at day 10 , in an almost hypoxic atmosphere in both washing treatments. In sliced carrot differences in oxygen levels were observed between calcium lactate and chlorine treated samples only on the first day after treatment. Carbon dioxide production was significantly higher in carrots treated with calcium lactate than chlorine over the 10 days storage. At days 7 and 10, the levels of carbon dioxide were in agreement with recommended $\mathrm{CO}_{2}$ levels $(15-20 \%)$ for fresh sliced carrot conservation (Fonseca et al., 1999).

The $\mathrm{pH}$ values in salad-cut lettuce at day 1 were significantly $(\mathrm{p}<0.05)$ lower in samples treated with calcium lactate than in samples treated with chlorine. In sliced carrots the $\mathrm{pH}$ values at day 1 were significantly $(\mathrm{p}<0.05)$ lower in samples treated with calcium lactate (5.72) than in samples treated with chlorine (6.0). Sliced carrots treated with chlorine maintained roughly constant $\mathrm{pH}$ values until the end of storage (6.12) whereas calcium lactate resulted in a decrease in $\mathrm{pH}$ (5.78).

An increase in dry matter was observed during storage for both carrot and lettuce samples $(\mathrm{p}>0.05)$, but with no significant differences between washing treatments. Exudate values in salad-cut Iceberg lettuce increased during storage but showed no significant differences between washing treatments. For sliced carrots, treatment with calcium lactate increased the initial exudates level significantly $(p<0.05)$. During storage, the exudates levels decreased for both treatments. Lightness index values $\left(\mathrm{L}^{*}\right)$ were 
significantly higher in chlorine treated salad-cut lettuce (81.6) than in calcium lactate samples $(79.8)(\mathrm{p}<0.05)$. The high luminosity in lettuce treated with chlorine could be due to the bleaching effect of chlorine on the tissue. The $a^{*}$ parameter increased significantly $(\mathrm{p}<0.05)$ during storage, with no significant effect due to the washing treatment. The increase in $\mathrm{a}^{*}$ (greenness to redness) is related to the appearance of browning. Similarly, total colour difference $(\Delta \mathrm{E})$ (Fig. 2) showed no difference between chlorine and calcium lactate treated samples over the 10 days of storage. For sliced carrots the $\mathrm{L}^{*}$ index showed significant differences between treatments $(\mathrm{p}<0.05)$. Throughout the storage period luminosity increased in chlorine-treated carrots while luminosity decreased in calcium lactate treated carrots. The increase in the $\mathrm{L}^{*}$ could be due to white surface development in chlorine treated samples (Mei et al., 2002). This process did not affect calcium lactate samples, perhaps due to an inhibitory effect of calcium lactate on lignification (Bolin and Huxoll, 1991). The greenness-redness parameter ( $\left.a^{*}\right)$ decreased significantly $(\mathrm{p}<0.05)$ from day 1 to day 7 in sliced carrots treated with both chlorine and calcium lactate. At day 10 , the samples treated with calcium lactate maintained a* values whereas $a^{*}$ decreased in the samples treated with chlorine. This $a^{*}$ decrease could be associated with a carotenoid loss in sliced carrots (Table 1). $\Delta \mathrm{E}$ showed significant differences $(p<0.05)$ between treatments, whereas the samples treated with calcium lactate showed a slight increase in colour during the 10 days of storage; the carrots treated with chlorine had higher $\Delta \mathrm{E}$ values that increased significantly during storage (Fig. 2).

Texture was analysed using a puncture cell attachment. The maximum puncture load $(\mathrm{kN})$ was measured as a crispiness parameter in salad-cut lettuce (Fig. 3-1). Significant differences between treatments were not observed $(\mathrm{p}>0.05)$, although the highest values were found in lettuce treated with calcium lactate.

Sensory analysis was used to analyse the quality of fresh processed (salad-cut) lettuce and sliced carrots over 10 days (data not shown). The general appearance is the main attribute that consumers use to evaluate the quality of vegetables and fruits, since people "buy with their eyes" (Willock, 1995; Abbott, 1999). Salad-cut lettuce showed lower scores for appearance at the end of the storage period than at days 1 to 7 . Acceptability was significantly dependent on storage time but not on treatment. The panel did not find differences in taste during storage although the off-odour increased significantly at day 10 . The development of off-odours may be due to the high concentrations of carbon dioxide and low levels of oxygen in the package at the end of the storage time (Fig. 1). The browning scores showed no difference during storage or between treatments. The low oxygen atmospheres developed inside the storage bags could have reduced enzymatic discoloration because oxygen is a necessary substrate for the browning reaction (Kader, 2002). For sliced carrots, the panel did not find significant differences in appearance between treatments during storage. At day 10, a significant change in browning, texture, acceptability, taste and odour was observed.

Texture enzymes related, PME (Fig. 4) did not show significant differences between treatments or changes during storage for both vegetables $(\mathrm{p}<0.05)$.

In cut-salad lettuce, initial PPO values were higher in lettuce treated with calcium lactate than in lettuce treated with chlorine, at day 3 the control and the calcium lactate treated lettuce gave very similar values, decreasing during storage in both cases. In sliced carrot, the initial PPO activity values were higher in chlorine than in calcium lactate treated samples, but the differences were not significant $(\mathrm{p}>0.05)$. The POD activity in salad-cut lettuce chlorine treated samples showed higher POD values than the salad-cut lettuce treated with calcium lactate. In carrots, the POD activity was low. This was expected since peeling removes the bulk of POD activity (Lepedus et al, 2004). Carotenoid content was significantly reduced by chlorine treatment $(p<0.05)$ compared to calcium lactate treatment. This was a significant advantage for calcium lactate treatment over chlorine treatment. This was consistent with colour measurements which showed significantly higher $a^{*}$ values for calcium lactate treated samples than chlorine treated samples. Ascorbic acid (Table 1) in both treatments decreased during storage $(p<0.05)$ in salad-cut lettuce and sliced carrots. 
In both vegetables, differences in ascorbic acid content between treatments were not found. Cryo-SEM analyses showed in salad-cut lettuce that after the treatment, samples treated with chlorine had a higher loss of turgor than samples treated with calcium lactate (Fig. 5). The cells of calcium lactate salad-cut lettuce presented a rounder shape than the chlorine samples.

In salad cut lettuce, mesophile counts were measured during storage at $4{ }^{\circ} \mathrm{C}$ over 10 days (Fig. 6). Initial values were in agreement with other authors who describe $10^{5}$ as a normal initial total count. Both treatments showed similar values at the end of the storage period. The values reached were considered acceptable to the consumer at the end of 10 days storage. The profile of mesophile counts was similar for both treatments although calcium lactate treated samples showed a transient increase at day 7 of storage. Although different authors have related an increase in mesophile counts with quality losses we have shown that quality is not different between treatments despite the transient increases observed. The psycrophiles (Fig. 6) represent an important group of organisms in fresh vegetables, because, although insignificant flora at the beginning of storage, they represent an important group at the end of storage and are related to quality retention. The psycrophiles profile showed no significant differences between treatments, reaching similar values at the end of the storage time. Lactic acid bacteria counts were very low at all times during storage (data not shown). Sliced carrots showed the same behaviour as lettuce for mesophiles and psychrophiles (Fig. 5). Although the carrots treated with chlorine had higher counts than calcium lactate for mesophiles and psychrophiles this was not significant. At the end of storage, both treatments showed similar values and are considered as acceptable to the consumer.

\section{CONCLUSION}

The main conclusion is that the calcium lactate is a suitable washing treatment for fresh cut, packaged, lettuce and carrots. Calcium lactate $(3 \%)$ was found to be just as useful as chlorine $(120 \mathrm{ppm})$ to extend the quality retention of fresh cut salad vegetables. It has advantages over chlorine in certain areas. Calcium lactate washing treatments avoids the post treatment bleaching effect in salad-cut lettuce and the appearance of whiteness on surfaces for sliced carrots. Calcium lactate enhanced and/or maintained nutritional value during storage in all samples, especially in sliced carrots where the carotenoids (which have a high antioxidant capacity) gave higher values than chlorine treated sliced carrots at the end of storage. A high quality product with a high retention of nutritional value indicates that calcium lactate is a viable alternative to chlorine, alone or combined with other novel washing treatments (ozone, irradiation, etc.).

\section{ACKNOWLEDGEMENTS}

This research was supported by a Technological Sector Research grant (20022006). The authors thank Amcor-Flexibles for providing of package films and Dr. Jose Barat Baviera (University Politecnica of Valencia) for the advised in cry-SEM.

\section{Literature Cited}

Abbott, J.A.1999. Quality measurement of fruits and vegetables. Postharvest Biol. Technol. 15:207-225.

AOAC. 1995. Official methods of analysis. Association of Official Analytical Chemists, $16^{\text {th }}$ ed., Washington DC.

Artes, F., Martinez, J., and Marin, J.G. 1999. Quality changes in minimally processed "Romaine" lettuce as affected by several treatments, in quality management of fruits and vegetables. p.115-118. In: M. Hagg, R. Avenhainen, A.M. Evers and K. Tikkala (eds.), Agri-Food quality II, London: The Royal Society of Chemestry.

Beuchat, L.R. 1999. Survival of Escherichia coli O157:H7 in bovine faeces applied to lettuce and ineffectiveness of chlorinated water as a disinfectant. J. Food Prot. 62:845849.

Bolin, H.R. and Huxoll, C.C. 1991. Effect of preparation procedures and storage 
parameters on quality retention of salad-cut lettuce. J. Food Sci. 56:416-418.

Carlin, F. and Nguyen-the, C. 1999. Minimally processed produce - microbiological issues. Proc. of Intl. Conf. on Fresh-Cut Produce. Campden and Chorleywood, UK.

Fonseca, S.C., Oliveira, F.A.R., Brecht, J.K., and Chau, K.V. 1999. Development of perforation-mediated modified atmosphere packaging for fresh-cut vegetables. p. 389404. In: F.A.R. Oliveira and J.C. Oliveira, Processing Foods. New York: CRC Press.

Gross, J. 1991. Carotenoids. In: Van Nostrand Reinhold (ed.), Pigments in Vegetables: Chlorophyllase and Carotenoids, New. York.

Kader, A.A. 2002. Postharvest biology and technology: an overview. p.39-47. In: A.A. Kader (ed.), Postharvest Technol. of Hort. Crops, Univ. of California, Oakland.

Kimball, D.A. 1991. Citrus processing-quality control and technology. Van Nostrand Reinhold, New York.

Luna-Guzman, I. and Barrett, D.M. 2000. Comparison of calcium chloride and calcium lactate effectiveness in maintaining shelf stability and quality of fresh-cut cantaloupe. Postharvest Biol. Technol. 19:61-72.

Lepeduš, H., Cesar, V. and Krsnik-Rasol, M. 2004. Guaiacol peroxidases in carrot (Daucus carota L.) root. Food Technol. Biotechnol 42:33-36.

Mei, Y., Zhao, Y., Yang, J. and Furr, H.C. 2002. Using edible coating to enhance nutritional and sensory qualities of baby carrots. J. Food Sci. 67:1964-1967.

Page, T., Harris, R.H. and Epstein, S.S. 1976. Drinking water and cancer mortality in Louisiana. Science 1993:55-57.

Rolle, R.S. and Chism, G.W. 1987. Physiological consequences of minimally processed fruits and vegetables. J. Food Qual. 10:157.

Saftner, R.A., Baj, J., Abbott, J.A. and Lee, Y.S. 2003. Sanitary dips with calcium propionate, calcium chloride, or calcium amino acid chelates maintain quality and shelf stability of fresh-cut honeydew chunks. Postharvest Biol. and Technol. 29:257269.

Tan, B.K. and Harris, N.D. 1995. Maillard products inhibit apple polyphenoxidase. Food Chem. 53:267-273.

Willock, F. 1995. Evaluation of microbial and visual quality of minimally processed foods: a case study on the product life cycle of cut endive. Doctoral thesis. Catholic University of Leuven, Leuven, Belgium.

\section{$\underline{\text { Tables }}$}

Table 1. Carotenoids and ascorbic acid content in sliced carrots treated with calcium lactate $(3 \%)$ and chlorine $(120 \mathrm{ppm})$ at the end of the 10 day storage at $4{ }^{\circ} \mathrm{C}$.

\begin{tabular}{|l|c|c|c|c|}
\hline Treatment & \multicolumn{2}{|c|}{ Carotenoids (mg/g) } & \multicolumn{2}{c|}{ Ascorbic Acid (mg/g) } \\
\hline & Day 1 & Day 10 & Day 1 & Day 10 \\
\hline Calcium Lactate & $13.36 \pm 0.58^{\mathrm{a}, \mathrm{B}}$ & $9.70 \pm 0.30^{\mathrm{b}, \mathrm{B}}$ & $0.045 \pm 0.004^{\mathrm{a}, \mathrm{A}}$ & $0.032 \pm 0.004^{\mathrm{b}, \mathrm{A}}$ \\
\hline Chlorine & $11.61 \pm 0.35^{\mathrm{a}, \mathrm{A}}$ & $7.76 \pm 0.30^{\mathrm{b}, \mathrm{A}}$ & $0.052 \pm 0.003^{\mathrm{a}, \mathrm{B}}$ & $0.032 \pm 0.003^{\mathrm{b}, \mathrm{B}}$ \\
\hline
\end{tabular}

*Values followed by the same letter are not significantly different. Lower case letter is used for storage and upper case letter for treatment. 


\section{Figures}

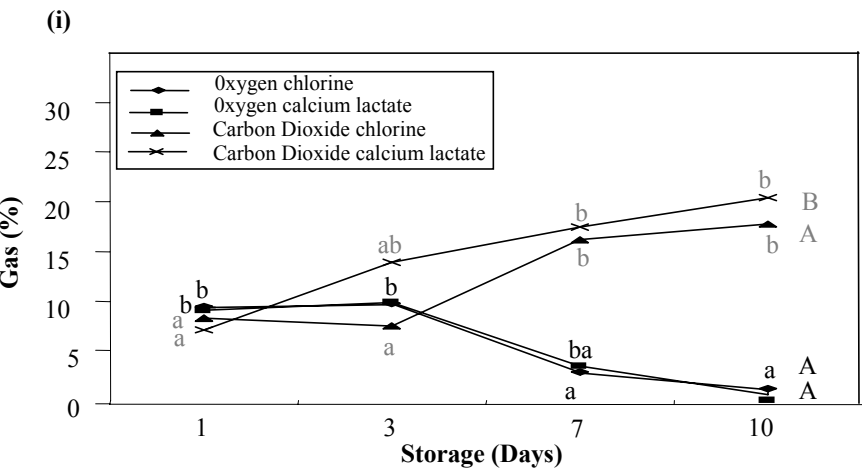

(ii)

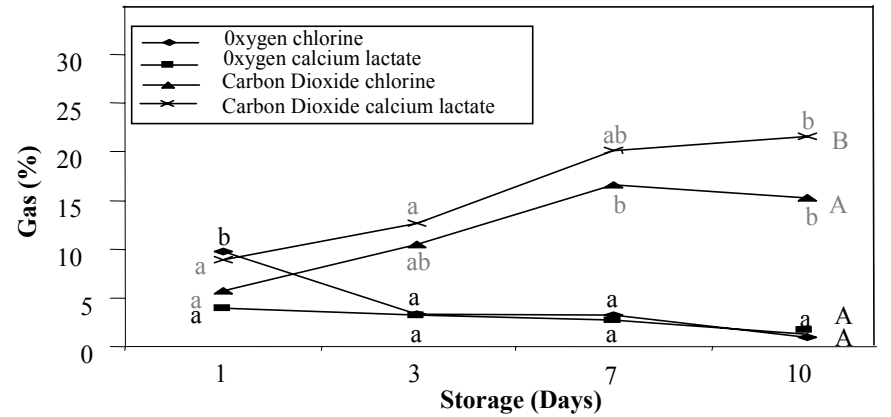

*Points designated by the same letter are not significantly different ( $\mathrm{p}>0.05)$. Lower case letter are used for comparisons during storage and upper case letter for treatment comparisons. Black letters are refer to oxygen content while grey letters are used for carbon dioxide content

Fig. 1. Effect of washing treatments $(120 \mathrm{ppm}$ and $3 \%$ calcium lactate at room temperature) on the oxygen and carbon dioxide gas content (\%) inside packages during 10 days of storage at $4{ }^{\circ} \mathrm{C}$; for salad-cut lettuce (i) and sliced carrot (ii).

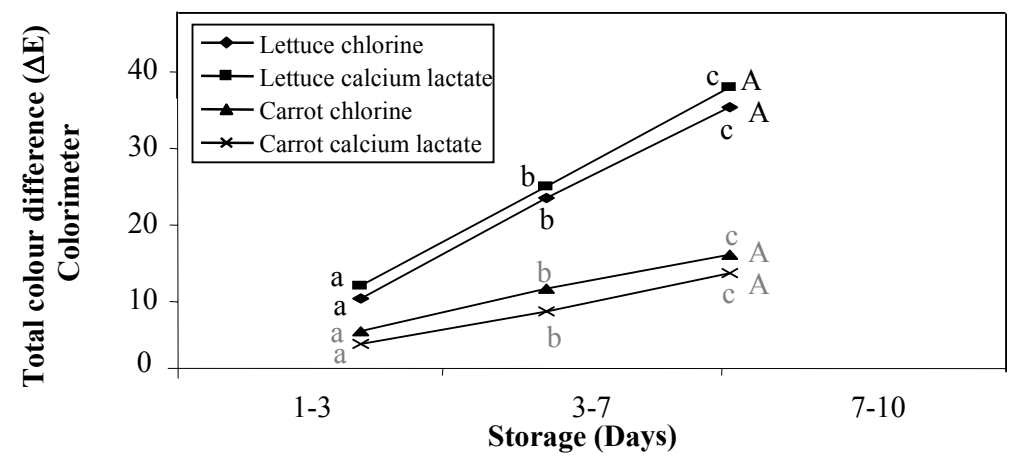

*Points designated by the same letter are not significantly different $(\mathrm{p}<0.05)$. Lower case letter are used for comparisons during the storage and upper case letter for treatment comparisons.

Fig. 2. Variation of colour during storage at $4{ }^{\circ} \mathrm{C}$ for salad-cut lettuce treated with $120 \mathrm{ppm}$ of chlorine and $3 \%$ of calcium lactate as washing treatments. 
(i)

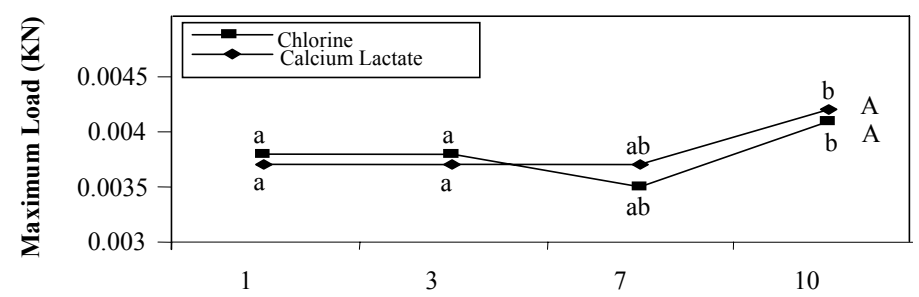

(ii)

Storage (Days)

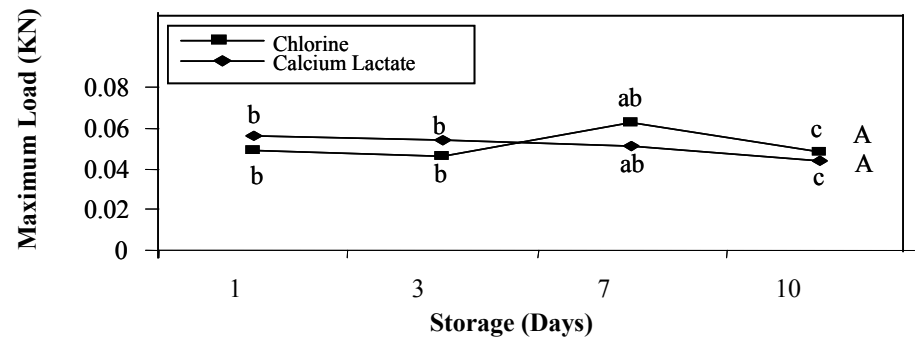

*Points designated by the same letter are not significantly different $(\mathrm{p}<0.05)$. Lower case letter are used for comparisons during the storage and upper case letter for treatment comparisons.

Fig. 3. Effect of storage and treatment (chlorine $120 \mathrm{ppm}$ and calcium lactate at $3 \%$ ) on the maximum load $(\mathrm{kN})$ obtained with a puncture cell in salad-cut lettuce (i) and sliced carrots (ii) storage at $4{ }^{\circ} \mathrm{C}$ for 10 days of storage.
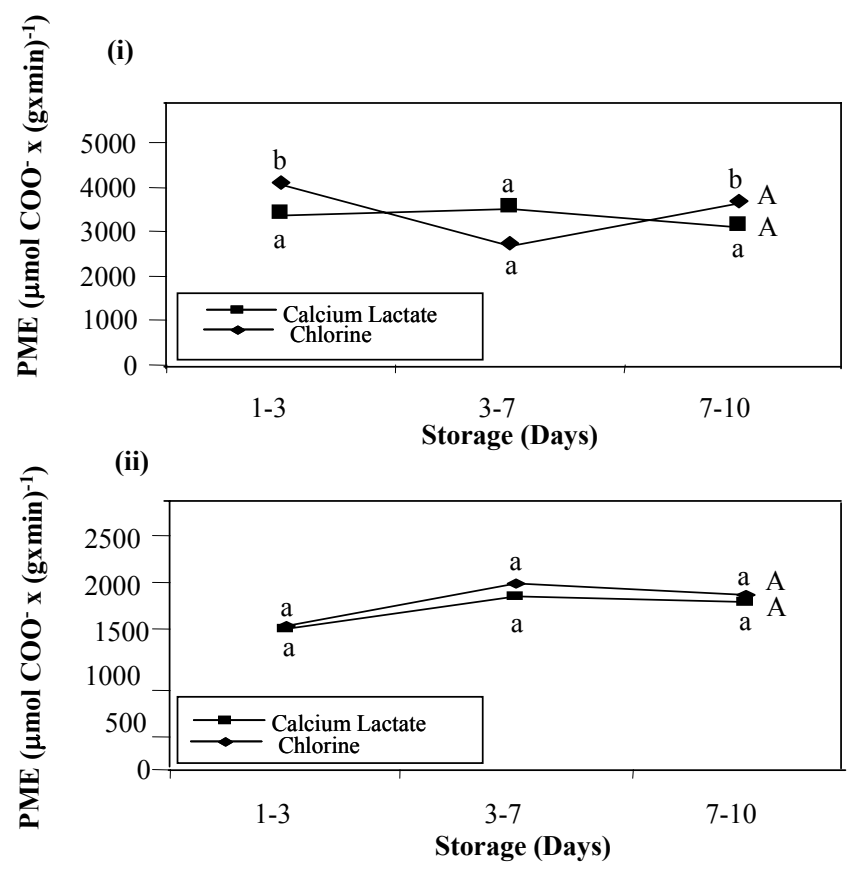

*Points designated by the same letter are not significantly different $(\mathrm{p}<0.05)$. Lower case letter are used for comparisons during the storage and upper case letter for treatment comparisons.

Fig. 4. Pectin methyl esterase (PME) activity values was analysed in salad-cut Iceberg lettuce (i) and in sliced carrot (ii) treated with $120 \mathrm{ppm}$ chlorine and $3 \%$ of calcium lactate washing treatment. The activity was expressed as $\mu \mathrm{mol} \mathrm{COO}-\mathrm{x} \mathrm{g}$ min -1 . The activity was measured over 10 days storage at $4{ }^{\circ} \mathrm{C}$. 

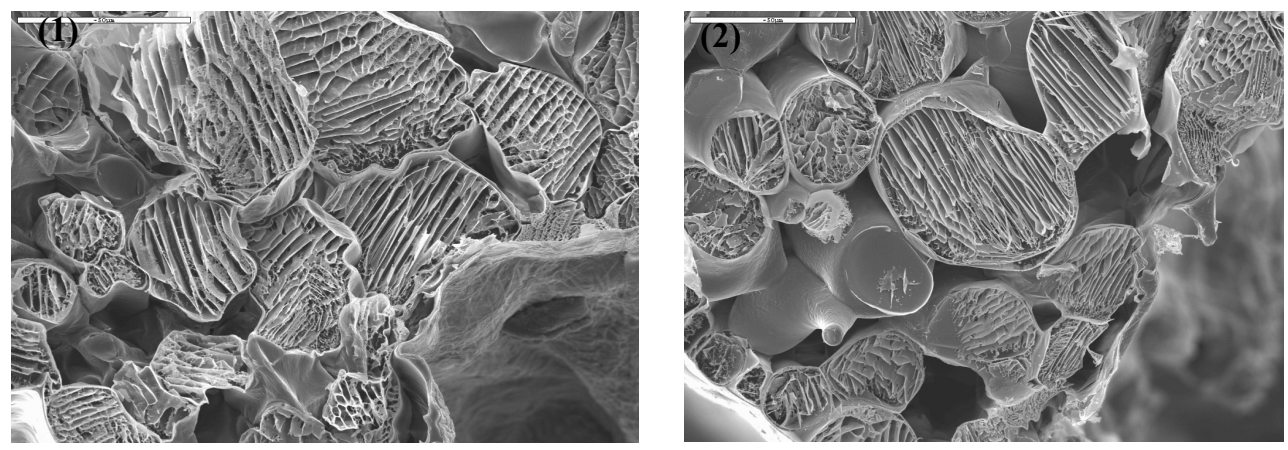

Fig. 5. Cryo-SEM analysis salad-cut Iceberg lettuce treated with chlorine (1) and calcium lactate (2) after the treatment.
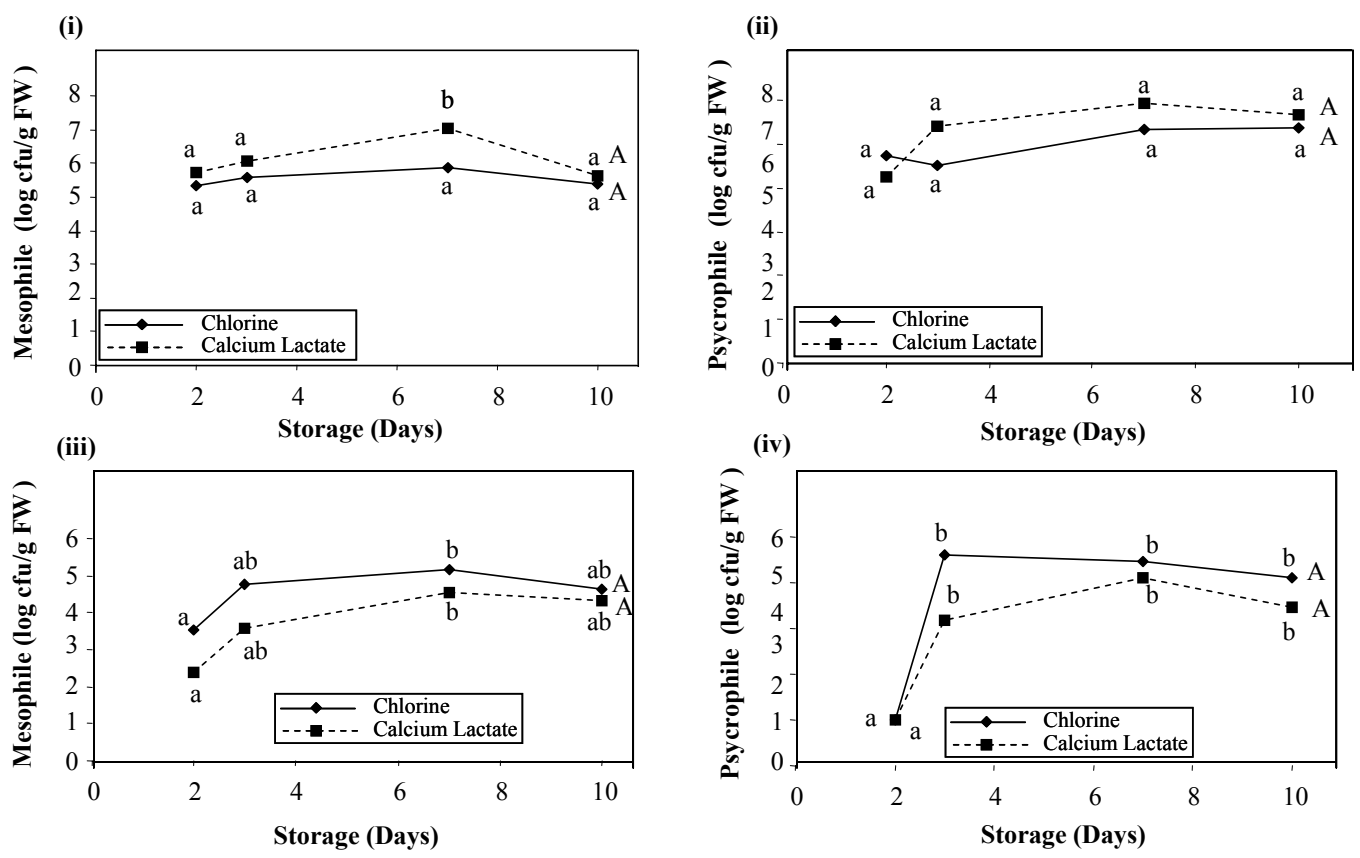

*Points designated by the same letter are not significantly different $(\mathrm{p}<0.05)$. Lower case letter are used for comparisons during the storage and upper case letter for treatment comparisons.

Fig. 6. Survival of microorganism during storage of minimally processed salad-cut lettuce ( $\mathrm{i}$ and ii) and sliced carrots (iii and iv) washing in $120 \mathrm{ppm}$ of chlorine and $3 \%$ of calcium lactate over 10 storage days. 